\title{
Sensitivity Testing as a Means of Differentiating the Various Forms of Leprosy Found in Nigeria
}

\author{
D. G. JAMISON \\ Department of Human Anatomy, University of Oxford, England
}

\begin{abstract}
In this study, tests of cutaneous sensation carried out with nylon threads on a group of healthy Nigerian subjects and 2 groups of leprosy patients have shown that the patients with lepromatous leprosy manifested increased cutaneous sensitivity, and further that a progressively increasing number of positive responses indicated lepromatous reactivation.
\end{abstract}

Danielssen and Boeck, in 1848, and Virchow, in 1864, described the alterations in cutaneous sensation and the involvement of the peripheral nervous system in leprosy. Since that time more and more evidence has accumulated to show that the peripheral sensory nerves of the skin are destroyed in tuberculoid leprosy and partially destroyed in borderline or dimorphous leprosy, while recently an increase in the number of small nerve fibres in the dermis at certain stages of lepromatous leprosy has been demonstrated.

The object of this paper is to describe a method of testing one aspect of cutaneous sensation in a roughly quantitative way, to show the pattern of responses to this test in different parts of the body in a series of normal Nigerian volunteer subjects, and to contrast these findings with those in a series of leprosy patients from the same racial and economic background. It is hoped to show that inforination about the type of leprosy, the progress under treatment, and any reactivation of the disease may be obtained by means of this simple test, and that the test may be of value where laboratory facilities are not easily available.

\section{MATERIALS AND METHODS}

The testing stimulators used are illustrated in Fig. 1. Six nylon threads of graded thickness are mounted in holders as shown, monofilament nylon sutures of thickness No. I to No. VI being used. Fig. 2 illustrates the skin areas tested

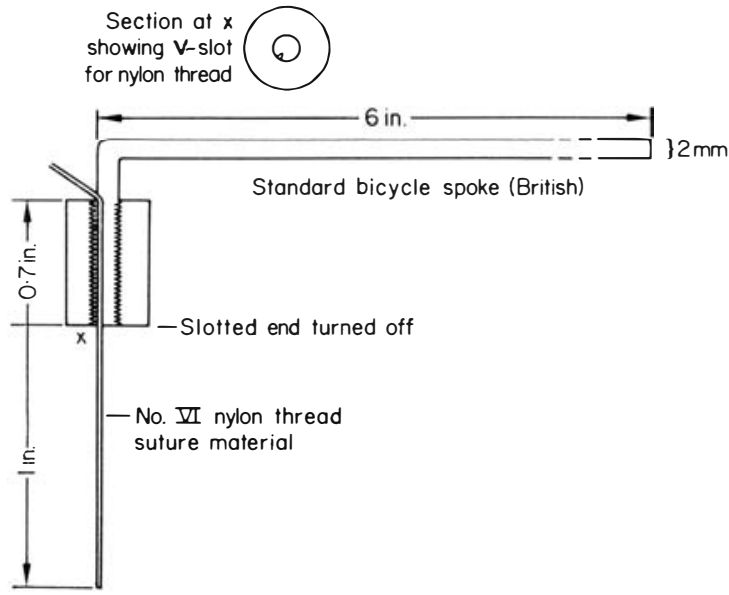

FIG. I

The stimulator.

in the healthy Nigerian volunteers. This group consisted of 15 men attending a course for dispensary attendants at Kaduna in Northern Nigeria, 7 women attending a child-welfare clinic in Katsina Province of Northern Nigeria, and 5 schoolboys from the junior primary school at Rimi, also in Katsina Province. All 27 subjects had been medically examined and found free of disease, and none had any family or house contact with leprosy.

The 16 leprosy patients studied can be divided into 2 groups: (A) 4 patients all from Katsina Province, all untreated when first investigated, and all re-investigated after one year and again after 2 years of regular out- 

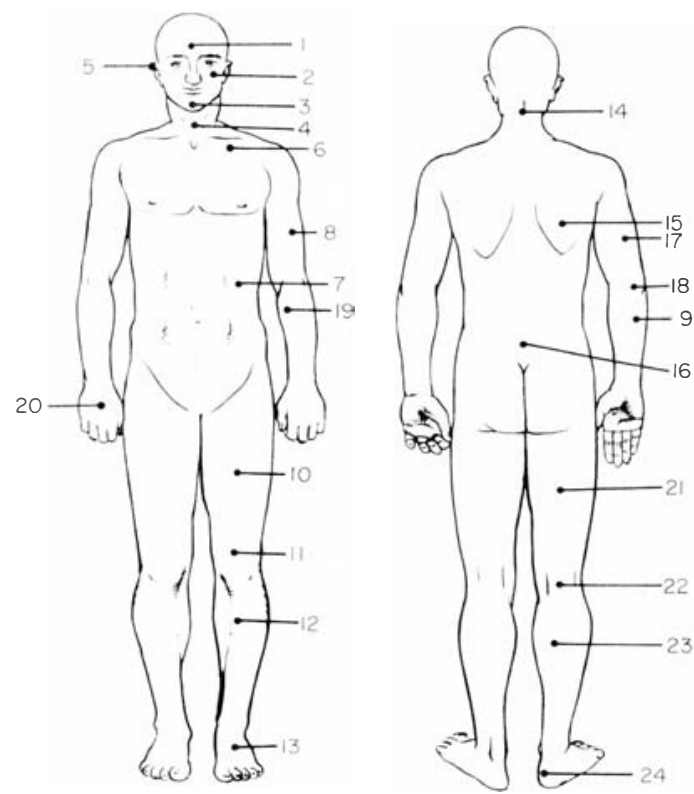

Fig. 2

Skin areas tested in normal subjects.

patient treatment with dapsone. At each investigation biopsy specimens of the tested skin areas were taken and examined for the presence of mycobacteria and the distribution of nerve fibres; and (B) 12 patients taken from among those attending out-patient treatment centres in Katsina Province. All 12 were tested with lepromin and all were examined by means of skin smears for the presence of mycobacteria.

In the normal series the sensitivity test was carried out as follows. A skin area $2.5 \mathrm{~cm}$ (1 in.) in diameter was selected and lightly shaved; where possible corresponding areas on the right and left sides of the body were similarly prepared. The volunteer was shown the stimulators, reassured that no painful sensation would result from their application, and told to indicate with one finger wherever he felt they had touched him. Next he was blindfolded and each of the 6 nylon stimulators was applied 3 times at random to the shaved area; from time to time the stimulator was applied to the corresponding area on the opposite side of the body. Each stimulator was delivered at right angles, allowed to bend to the same degree, kept in contact for the same length of time, and not dragged over the skin surface. The results were recorded as "felt" or "not felt"; minor degrees of misreference were recorded as "felt" and gross misreference or no response as "not felt". Failure to recognize stimuli delivered to the opposite side of the body invalidated the test.

In the leprosy patients with circumscribed skin lesions the test was carried out at 3 sites, namely, on the skin of the lesion, on the normal skin beyond the leprosy lesion on the same side of the body, and on the normal skin over a comparable area on the opposite side of the body. In those with generalized lepromatous leprosy the reaction of the infiltrated skin of a particular area on the right side of the body was compared with that on a similar area on the left side.

TABLE I

Responses of 27 subjects (15 males, 7 females, 5 children) to stimuli with nylon thread

\begin{tabular}{|c|c|c|c|c|c|c|c|c|}
\hline \multirow{2}{*}{\multicolumn{3}{|c|}{ Site stimulated }} & \multicolumn{6}{|c|}{ Thread number } \\
\hline & & & I & II & I I I & IV & $\mathrm{V}$ & VI \\
\hline Brow & . & . & 75 & M & $M$ & $M$ & $M$ & M \\
\hline Cheek & . & . & 79 & M & $M$ & M & $M$ & M \\
\hline Chin & .. & $\ldots$ & 77 & $M$ & $\mathrm{M}$ & $M$ & $\mathrm{M}$ & $M$ \\
\hline Anterior neck & . & $\ldots$ & 70 & $M$ & $M$ & W & 11 & M \\
\hline Below clavicle & . & $\ldots$ & 63 & 79 & M & M & $M$ &.$M 1$ \\
\hline Over lower ribs & $\ldots$ & $\ldots$ & 53 & 75 & M & $M$ & $\mathrm{M}$ & M \\
\hline Front of thigh & . & $\ldots$ & 57 & 75 & M & $\mathrm{M}$ & M & $M$ \\
\hline Above knee & . & .. & 54 & 76 & 80 & $\mathbf{M}$ & $M$ & M \\
\hline Front of tibia & . & . & 43 & $6(1)$ & 65 & $M$ & M & M \\
\hline Dorsum of foot & $\ldots$ & $\ldots$ & 57 & 76 & 77 & M & $M$ & $M$ \\
\hline Front of upper & arm & $\ldots$ & 58 & 68 & M & $M$ & $M$ & M \\
\hline Flexor forearm & $\ldots$ & . & $4 \cdot 2$ & $7 \cdot 2$ & M & $\mathrm{M}$ & M & $\mathrm{M}$ \\
\hline Back of upper & arm & . & 46 & 74 & $M$ & $\mathrm{M}$ & $\mathrm{M}$ &. $\mathrm{ll}$ \\
\hline Flbow & $\ldots$ & $\ldots$ & 0 & 0 & 14 & 46 & 80 & $M$ \\
\hline Back of forearn & & . & 78 & $\mathbf{M}$ & $\mathrm{M}$ & $\mathbf{M}$ & M & $M$ \\
\hline Back of hand & . & . & 39 & 68 & M & M & M & $M$ \\
\hline Back of thigh & . & $\ldots$ & 60 & 72 & $\mathrm{M}$ & $\mathbf{M}$ & $\mathrm{M}$ & MI \\
\hline Calf $\quad \ldots$ & . & $\ldots$ & 32 & 57 & 79 & M & M & $M$ \\
\hline Over heel & . & . & 28 & 51 & 77 & $\mathrm{M}$ & M & M \\
\hline Ear & . & $\ldots$ & $M$ & M & M & M & $\mathrm{M}$ & M \\
\hline Posterior neck & $\ldots$ & $\ldots$ & 53 & 77 & M & $\mathrm{M}$ & M & $M$ \\
\hline Scapula region & . & $\ldots$ & 60 & 76 & $\mathrm{M}$ & M & $\mathrm{M}$ & M \\
\hline Lumbar region & . & .. & 54 & 73 & $\mathrm{M}$ & $M$ & M & $M$ \\
\hline Back of knee & . & $\ldots$ & M & $\mathbf{M}$ & $\mathrm{M}$ & M & $M$ & $M$ \\
\hline
\end{tabular}

M, maximum response by all subjects.

Figures indicate number of responses to 81 stimuli. 


\section{RESULTS}

The results of the test in the 27 normal volunteers are shown in Table 1. Each stimulator was applied 3 times to each area in each of the 27 volunteers. The letter M represents 81 responses to 81 stimuli, i.e. the maximum possible. The figure 75 in Column I indicates that 75 responses were obtained to stimulator No. I out of a total of 81 stimulations.

A review of these results as a whole reveals that the face, ears and back of the knee were the most responsive sites, while the skin of the legs and particularly of the elbow was the least responsive.

The 4 leprosy patients in Group A were: (1) a woman with a single tuberculoid lesion, a positive lepromin test result, and a patch on the flexor surface of the forearm; (2) a man with borderline lesions, a positive lepromin test, and multiple patches on the forearm; (3) an older man with possibly lepromatous macules, a negative lepromin test, and multiple small macules on the forearm; and (4) a young man with advanced lepromatous leprosy, a negative lepromin test result, and generalized lepromatous infiltration of the skin of the whole body.

Fig 3 summarizes the results of the sensory testing in these 4 patients at 3 sites, namely, (a) the skin of the forearm lesion, $(b)$ the skin beyond the lesion, and $(c)$ the skin of the opposite forearm.

The first patient illustrates the pattern of responses obtained in tuberculoid leprosy. The lesion is initially anaesthetic while the unaffected skin on both forearms gives responses that are within normal limits. As the result of

$\begin{array}{ccc}\text { Ist examination } & \text { 2nd examination } & \text { 3rd examination } \\ \text { a, Centre of lesion; } & b \text {, normal beyond; } & c \text {, normal opposite side }\end{array}$
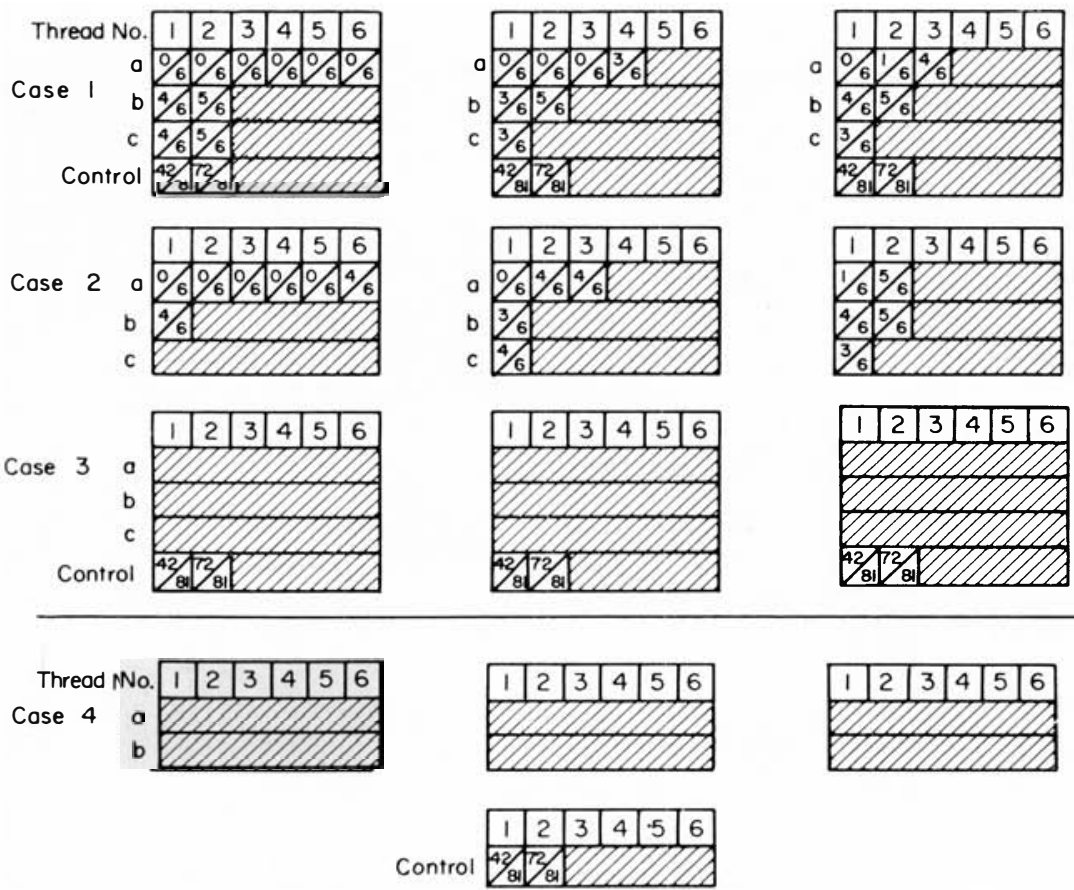

o,Infiltroted skin right forearm; $b$, infiltrated skin left foreorm.

Fig. 3

A breakdown of normal patterns of response in the 3 groups not included. 
treatment, however, the lesion gradually becomes more responsive while the normal skin remains unchanged. Patient No. 2 at the first examination shows anaesthesia of the lesion, but a greater number of responses to stimuli on the opposite forearm compared with the control series. However, with treatment the number of responses from the lesion increases and the pattern from the skin of both forearms returns to normal. In the 3rd and 4th patients the skin of both forearms consistently responds to all stimuli and this pattern is in no way altered by treatment.

In Group B, 8 of the 12 patients showed a general lepromatous infiltration of the skin of the whole body. In spite of variable periods of treatment, mycobacteria could still be found in skin smears. All 8 failed to respond to lepromin. In all 8 patients the same increase in the number of responses to stimuli as compared with the normal series was observed even though the skin areas tested ranged all over the body.

\section{CONCLUSION}

It is concluded that an increased number of responses compared with the normal established pattern indicates the presence of lepromatous leprosy, and that a progressively increasing number is an indication of lepromatous activation.

\section{ACKNOWLEDGEMENTS}

I am grateful to Dr. A. G. M. Weddell for all his encouragement and practical assistance in devising this test and in planning these experiments, and to Miss Court for preparing the figures and tables.

\section{REFERENCES}

DANiElssen, C. c. and BOEk, w. (1848). Traité de la Spedalskhed. Paris: Baillière.

virchow, R. (1864). Die krankhaften Geschwulste. Vol. 2. Berlin: Hirschwald. 